\title{
KAVRAMSAL SANAT
}

\author{
Binnaz Koca*1 \\ *İnönü Üniversitesi Güzel Sanatlar Eğitimi, Resim İş Eğitimi Programı, Malatya / Türkiye
}

\begin{abstract}
Özet
Kavramsal Sanat 1960'larda sanatın anlatım dilini alışageldik anlatımının dışına çıkartır. Fetişleştirilmiş olan sanat nesnesini artık meta olmaktan kurtararak sanatın düşünsel bir süreç olduğunu söyler. Kavramsal sanatta nesnenin felsefe ve dille şekillendirilmesi de önemli bir ayrımdır. Bu ilişki sıradan olana ve gündelik hayatta yaşanılanlara da ilgi duyulmasını sağlamaktadır ve hiçbir şeyin asıında sıradan olmadığını düşündürtür. Çok dilli ve çok yönlü olan bu tutum, kavramsalın düşünsel bir süreçle algılanmasını da beraberinde getirir. İmgenin ortadan kalktığı, yerine metnin girdiği ve önceliğin kavrama verildiği üretim şekli artık her tür malzemede, durumda, biçimde kendisini ortaya koymaktadır. Sanat ve estetik ilişkisi yeniden sorgulanmakta, ortaya çıkan işlerde aranması gereken "estetik haz" ve "güzel", yerini "kavram"ın önemli olduğu bir düşünce sürecine bırakmaktadır.
\end{abstract}

Anahtar Kelimeler: Kavramsal, Sanat, Resim

\section{CONCEPTUAL ART}

\section{Abstract}

Conceptual art in 1960's takes the art's expression language out it's usual expression. Saving the fetishized art object from being a meta, it says that art is a spiritual process. In conceptual art, object's formulation with philosophy and language is also an important distinction. This releationship also provides interest to the ordinary one and the things experience in Daily life and it makes us think that nothing is ordinary in fact. Attitude which is multilangual and multidirectional brings along the conceptual's being understood as a spiritual process. The shape of production that imagery's disappeared text's entered instead and priority's being given to concept puts forth itself in every material, position and form. The relation between art and esthetique is being interrageted again, esthetique pleasure and beautiful which are necessary to be looked for in the coming up Works are leaving it's place to the idea processthat concept's being important.

Keywords: Conceptual, Art, Painting

\section{Giriş}

Kavramsal sanat terimi, 1960 'ların ortalarında kendilerini alışılageldik sanat eseri biçiminde göstermeyen sanat eserleri için kullanılmaya başlanmıştır. Sanatın kuramsal yanını çözümlemeyi, yeniden tanımlamayı amaçlayan kavramsal sanat, mantık ve felsefeyle yakından ilişkilidir. Sanatçı, o güne kadar sanatta bulunan geleneksel malzemelerin ve biçimlerin dışında düşünmeye başlayıp düşüncelerini uygun malzemeler aracılığıyla ifade etmiştir. Kavramsal sanat, sanatın nesnesini fetişleşmiş bir nesne ya da meta olmaktan kurtarmayı amaçlar ve sanatın düşünsel bir süreç olduğunu göstermeye çalışır.

Norbert Lynton'ın ayrıntıı kavramsal sanat düşünceleri şu şekildedir: Kavramsal sanat, müzelerde izlenilen eserlere yapılan aşırı övgünün, birkaç saniyelik izlemle mümkün olamayacağını; sanatçının ününün, eserden duyulan hazzın yerini aldığını söyler. Kavramsal sanat bu durumu önlemeye çalışır. Sahip olunabilir, sergilenebilir nesneyi devreden çıkartır. Kavramsal sanat sanatın herhangi bir nesneyle ve de mekânla sınırlandıılamayacağı fikrini taşır. En etkili kavramsal sanat eserleri, sıradan şeylerle en uygun düşünceleri bir araya getiren işlerdir. Estetiği dışlayıp, sanatın bir zevk alma aracı olmadığını söylerken, klasik

\footnotetext{
${ }^{1}$ Yazışma yapılacak yazar: kocabinnaz@gmail.com
} 
anlamadaki sanattan en belirgin kopuşu yaşar. Bu bir maddesizlik değildir. Çünkü kavram, betimlemenin farklı bir biçimde içinde görünüşüdür. Önemsenen şey bu biçim değil, metinsel içeriktir. Metinsel içeriğin anlaşılmasında biçim bir araçtır. (Lynton, 1989:339,340,341)

Kavramın önemli olduğu, estetik olgusuna mesafeli duran kavramsal bir üretim olan kavramsal sanat "düşünsel olan bir sanat üzerine düşünme eylemidir". (Özgür, 2004) Sanatın ne olduğunun eleştirel bir bakışla sorgulanması, geleneksel yerleşmiş yöntemlerle yapılamazdı. Bu da kavramsal sanatın biçimsel sanatlara tamamen karşı durmasını getirmiştir. "Fikirler sanatı" olarak da tanımlanan kavramsal sanatı Kosuth ise tanımlama konusunda, "tanımlamak zorunda olmadığıma memnunum, artık sadece sanat var ve öyle adlandırabilirim" der.

Sanatın anlamı, tanımı üzerine tartışmaların Marcel Duchamp'ın “ Pisuarıyla başladığı bilinmektedir. Duchamp, düşüncenin yapıta dönüşmesinin yolunu açmıştır. Sanat ile yaşam arasındaki çizginin kaldırıması bu şeklide başlayıp kavramsal sanatçıların da sürdürdükleri ele alış şekline dönüşmüştür. Mehmet Ergüven, Duchamp'ın sanatından bahsederken; "(onu) Avant Garde olarak sınıflandırmamızı sağlayan bu düstur, sanat ile yaşam arasındaki sınır çizgisinin feshidir kuşkusuz" der. (Ergüven, 2003:274)

Kavramsal sanatın terim olarak yerleşmesinde Sol Lewitt'in payı büyüktür. Kendi çalışmalarının kavramsallığını vurgulamak için 1967 yılında ART FORUM dergisinde yayınlandığı "kavramsal sanat üzerine paragraflar" yazısından sonra bu terim, dönemin neredeyse tüm alternatif ifade biçimlerini karşılayan bir genel terim haline gelmiştir. Lewitt bu yazısında; düşünce ve kavramın işin en önemli yanı olduğunu, bütün karar ve planların baştan oluşturulup uygulamanın sadece bir formalite gereği olduğunu, dolayısıyla düşüncenin sanatı oluşturan bir makineye dönüşmüş olduğunu belirtmiştir. (Yılmaz, 2005:220) Joseph Kosuth da, 1969'da yayınlandığı makaleleri ile kavramsal sanatı sorgulamıştır. 1910'da şair Apollinaire "kavram resmi" diye bir terimi ilk kez kullanmıştı. Bu terimi kubizmi açıklamak için kullanmıştı ve düşüncesi şuydu: Varlık görüntülerin ötesindedir. Resimdeki varlık, zihinsel bir tasarımın sonucudur. Resim bir kavramın resmidir. Duyuma karşı zihni öne çıkartan bu düşünce, sanatın kavramsallığıyla da bazı benzerlikler taşımaktadır. Ama onun amacı, kübizmin felsefesini ortaya koymaktı. (Yılmaz, 2005:212)

1959 'da Henry Flynt "kavram sanatı" terimini bir Fluksus yayınında kullanmıştı. Yazısında şunları söylüyordu: "Müziğin malzemesinin tını olması gibi, sanatın malzemesi de her şeyden önce kavramdır. Kavramlar dil ile sıkı sıya bağlı oldukları için, kavram sanatı da malzemenin dil olduğu türden bir sanattır. Müzik, öncelikle tınıdan ibaret iken, kavram sanatının asıl meselesi dildir." (Yılmaz, 2005:216)

Farklı nedenlerden dolayı isimlendirilip kullanılan kavramasal sanat terimi, bu tanımlamalarla geleneksel anlamda bir biçimlendirmeyi işaret etmediğini hissettirmektedir. Kavramsal sanat ismi netleşmeden önce de yapılan işlerde bu geleneksel dışı yaklaşımları görmekteyiz. 1954 yılında Amerikalı besteci John Cage'in "4" "33" isimli sessiz müziği, kavramsal sanatın habercisi olarak nitelendirilmiştir. Kavramsal sanata; 1953 yılında Robert Rauschenberg'in "De Kooning'in desenini silerek kendi yapıtını oluşturmasını, Ad Reinhardt'ın 1954'te başlattığı "ikonografisiz ikonlar, saf, soyut, nesnesiz sanat nesneleri” olarak adlandırdığı aynı ölçülerde ve birbirinin tekrarı olan siyah resimlerini; Yues Klein'in 1958'de iris Clert galerisinde açtı̆̆ı "boşluk" sergisini, 1959'da Piero Manzani'nin farklı uzunluklarda kâğıtlar üzerine mürekkeple düz çizgiler çizip, bunları paketleyerek oluşturduğu sanat nesnelerini örnek gösterebiliriz. Duchamp'ın bu anlamda öncülüğünün sorgulanmasına gerek yoktur.

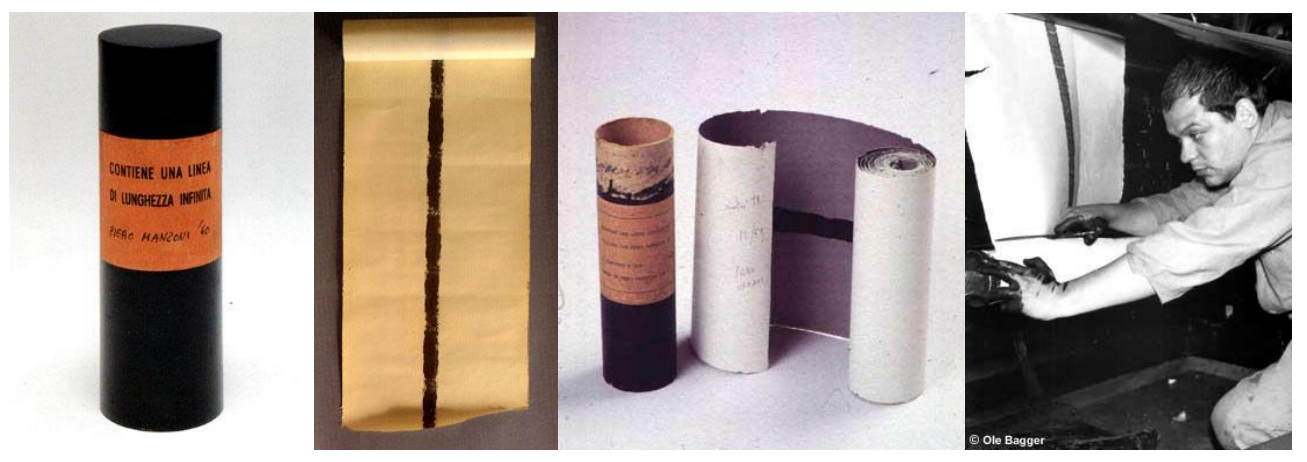

Resim 1. Piero Manzoni. 1959

“O; bütün yüzyılın büyük çağdaşıdır. Duchamp'ın kalabalık takipçilerine göre, sanatın edimi yapıt olarak belirtilebilen bir nesnenin imal edilmesinden ibaret değildir. Artık, bir hareketten, bazen küçük 
bir hareketten meydana gelmiştir. Bir nesnenin yerini değiştirme, yönünü ya da adını değiştirme ve böylece statüsünü dönüştürme hareketi, ya da zaten var olan imgelerin derlenmesi toplanması hareketi. Duchamp'ın ve Man Roy'un, ortamı yalayıp geçen ışık altında, büyük camın üstüne birikmiş bir toz yığınını gösteren, toz yetiştiriciliği (1920) adlı fotoğrafında, kendi haline bırakmanın, kendi oluşuna bırakmanın toz birikmesine göz yummanın, zaman damgasını göstermenin küçücük hareketi betimlenir. Bir şey yapmaktan kaçınmanın kendisi bir harekettir. Öyleyse eylemsizlik içinde bile sanatçı olunabilir. "sanatçı oluş" kalıcı bir durumdur. Başkasına aktarımaz bir niteliktir. Daha 1925'te Kurt Schwittera bunu ilan eder: "Bir sanatçının tükürdüğü her şey sanattır." (Gökteke,2011)

Sanatın tanımını yapmaya çalışanlar arasında bulunan sanat ve dil grubu da; Ludwig Wittgenstein Ferdinand de Saussure, Claude Levi- Strauss ve Roland Barthes'ın geliştirdiği dilbilimsel çözümlemeler ve göstergebilimden yararlanarak sanatı tanımlamaya çalışmışlardır. 1968'de Terry Atkinson, David Bainbridge, Michael Baldwin, Harold Hurrell gibi İngiliz sanatçılar, İngiltere'de sanat dil grubunu oluşturmuşlardır. Joseph Kosuth da derginin Amerikan editörüdür. Derginin ilk sayısı 1969'da çıkmıştır. (Atakan, 1998:44)

Atkinson, derginin ilk sayısında "kavramsal sanat hakkında yazdığı yazının bir kavramsal sanat olup olmayacağı sorusunu sordu. Resim kendine has anlatım şekliyle ve oluşturduğu dille karşısındakilere bir şeyler söyleyen yapıttı. Metnin dili yazınsaldı ve karşısındakilere bir şeyler söylüyordu. İkisi arasındaki fark biçimseldi. Metnin sanat nesnesi olamayacağını ama sanat yapıtı olabileceğini belirtti. (Yılmaz, 2005:217)

Sanat ve dil grubu bağlamından koparılan eserin değişime uğramasını, Bainbridge'in St.Martin sanat okulu heykel bölümünde yaptığı vinç’i çocuk parkına yerleştirmesi üzerinden sorgularlar. Duchamp'ın hazır nesnesiyle de ilişkilendirdikleri bu işi "hazır nesnenin nesnesi” şeklinde isimlendirmişlerdir. Duchamp'ın şişe rafı tamamen sanat dışı bir yaklaşımla üretilmişken, Bainbridge'nin vinç'i sanatsal bir yaklaşımla üretilmiştir. Ama bulundukları nokta yapılış amaçlarından o nesneleri uzaklaştırmıştır. Şişe rafı bir sanat kurumunda, vinç de çocuk parkında sergilenerek üretildikleri bağlamdan koparılmışlardır. Ancak yerleştirdikleri bağlamla sanatsal bir diğer yüklenebilirler veya kaybedebilirlerdi. (Atakan, 1998:46) Grup; iş üretmektense, sanatsal tartışmalara yönelerek sanat kavramını sorgulamayı daha çok önemsemiştir. Bu türden yapılan tartışmalar, dilbilimsel yaklaşımlarla geliştirilen çözümlemeler de sanat yapıtı sayılmıştır. Mel Bochner'e göre kavramsal sanatta olması gereken iki şey vardır. Birincisi, yapıtın dilsel bir karşılığının olması; ikincisi de yapıtın biricilikten kurtulmuş olmasıdır. Estetik hazzı dışlayan kavramsalcılardan olan Joseph Kosuth, "dil yoksa sanat da yoktur" der. (Antmen, 2009:195)

Kosuth, 1970 yılında sanat ve dil dergisinde yayınlandığı "felsefeden sonra sanat" başlıklı makalesinde Duchamp'dan önce ve sonra olmak üzere sanatı ikiye ayırır. Tanım resimlerinde bazı kavramları sorgulamış, "bir ve üç sandalye" gibi işlerinde de nesnenin kendisi, aynı boyutlarda nesnenin fotoğrafı ve nesnenin tanımını sergileyerek görsel algıdan dile, dilden kavrama uzanan süreçleri irdelemiştir. "... Sanat tanımının Duchamp'la birlikte sona erdiğine inanan Kosuth'un yapıtları, Duchamp'dan sonra sanatçının sanattan değil, "sanat kuramı zemininden hareket etmesinin zorunluluğu yönündeki inancının bir yansımasıdır" (Antmen, 2009:196).

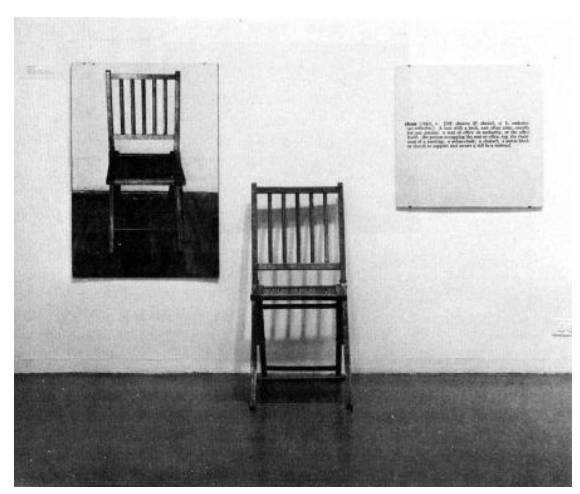

Resim 2. Joseph Kosuth.

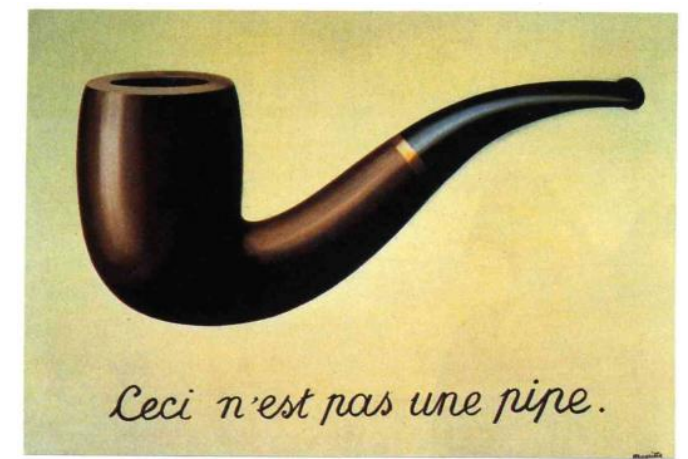

Resim 3. Rene Magritte "La Trahison des Images" ("The Treachery of Images") imgelerin ihaneti (1928-9) ya da "Ceci n'est pas une pipe" ("This is not a pipe") bu bir pipo değildir 
Yapıtın kendini çoğunlukla bir metinde ortaya koyduğunu söylemiştik. Bu metinlerle birlikte genellikle fotoğraflar kullanılır. Kullanılan fotoğrafları ya da biçimsel aktarımı imge olarak düşünmememiz gerekir. Joseph Kosuth'un "bir ve üç sandalye" gibi işlerinde, "gerçek, taklit, kopya ve temsil" (Yılmaz, 2005:226) sorgulaması yapılıyor. Kavramsal sanat ile birlikte gerçek algısının değiştiğini söyleyebiliriz. Bu durumun öncesi olarak da Rene Magritte'i gösterebiliriz. "imgelerin ihaneti" isimli çalışmasında bir pipo resmi, resmin altında da "bu bir pipo değildir" yazısını görmekteyiz. Görüneni yalanlar şeklindedir bu durum. Bir sorgu da oluşturur. Kosuth'ta olduğu gibi Magritte'de de temsil kavramıyla karşılaşırız. Bu pipo resmi; gerçeği değil, izleyicisine onun bir temsili olduğunu imler." Resimde gördüğümüz pipo, cebimizdeki pipodan daha gerçektir. Çünkü gördüğümüz şu ya da bu sapı olan, içi kirli ya da ağızlığı yerinden bir parça kopmuş belli bir pipo değil, genel bir pipoyu imlemektedir." (Lynton, 1989:182)

1969 'da boş bir ticaret bürosunda Seth Seige tarafından düzenlenen sergi, kavramsal sanatın tanınmasını sağlamıştır. Sergi davetiyesi, kavramsal sanatın biçimsel sanata karşı duruşunun göstergesi gibidir. Davetiye biçimsel olarak Don Graham'ın 1966'da yazdığı Schema başlıklı o şiirin görselliği gibidir. Davetiye şu şekildedir: (Gintz, 2010:155)

$\begin{array}{rll}0 & \text { OBJECTS } \\ 0 & \text { PAINTERS } \\ 0 & \text { SCULPTURES } \\ 4 & \text { ARTIST } \\ 1 & \text { ROBERT BARRY } \\ 1 & \text { DOUGLAS HUEBLER } \\ 1 & \text { JOSEPH KOSUTH } \\ 1 & \text { LAWRENCE WEINER } \\ 32 & \text { WORKS } \\ 1 & \text { EXHIBITION } \\ 2000 & \text { CATALOGS } \\ 44 E .52 S T & \text { NEW YORK } \\ 5-31 & \text { JANUARY 1969 } \\ \text { (212)2885031 } & \text { SETH SIEGELAUB }\end{array}$

1969 yılında gerçekleşen sanatsal olaylardan bir diğeri de Siegelaub'un düzenlediği sergidir. "Summer Show'da toplu bir sergi gerçekleşmeyip, katıııcı olan onbir sanatçının uygulamaları farklı yerlerde gerçekleştirilmiştir. Eleştirmen Lucy Lippard ve Siegelaub'un katkılarıyla düzenlenen sergilerde de serginin adı, düzenlenen kentin nüfusu oluyordu: Seattle için 557.087 ( Ekim 1969), Buones idaresi için 2.972.453) Kasım 1970) Sergilerin katalogları, sanatçıların sağladıkları Bristolden bireysel fişlerdir.

Robert Barry de nesnesiz işler üretmeye girişmişti. 1968'de naylon iplerden görünmez enstalâsyonlar yaptı, frekans dalgası vericileri ile yaptığı da yine görünmez işlerindendi. Böyle bir başka işin yapıldığını kanıtlayabilmek sadece resmi tarzda yazılmış bir rapor: "5 Mart 1969 sabahının bir anında atmosfere yarım metre küp helyum gazı salınmıştır." Görünmezlik devam etmiştir. (Gintz, 2010:155-162) Robert Berry'nin bu çalışmalarının nedenleri arasında, sanat ve dil grubunun diğer üyelerinin de yapmış oldukları yapıtın bağlam sorgulaması yatar. Berry, resim ve heykelin yapıldıkları yerden başka bir mekâna geçmesiyle anlamlarını kaybettiklerini fark etmiştir. Bu durum Barry'nin sanatın bakılacak bir şey olmadığını keşfetmesine neden olmuştur ve gözle görülmeyen malzemelerle çalışmaya başlamıştır. 


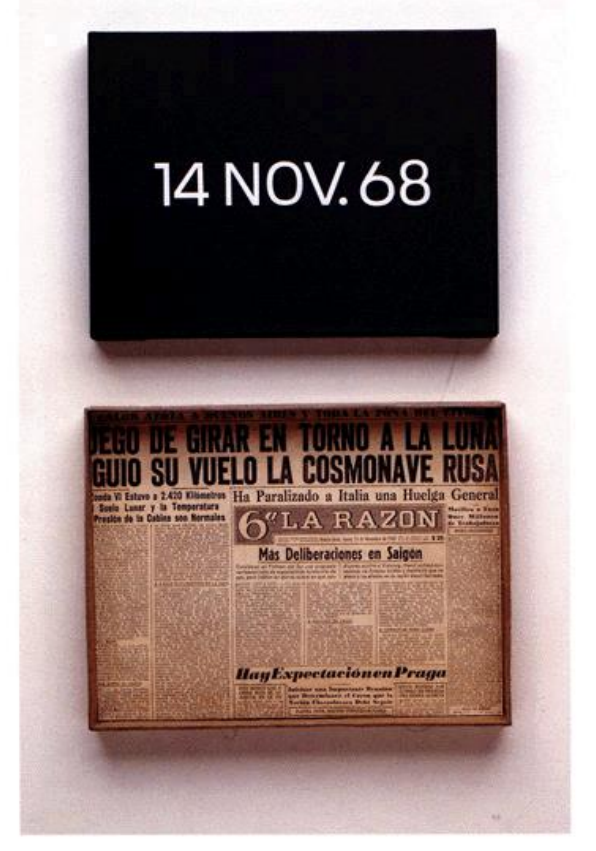

Resim 4. On Kawara

On Kawara işlerini, "bir gün" ismini taşıyan bir projeyle gerçekleştirmiştir. Her çalışma 24 saat içinde başlayıp bitme zorunluluğu taşımaktadır. Çalışma, o gün içinde bitmezse yok edilecektir. İşler siyah zemin üzerine o güne ait gün, ay ve yılın yazıımasıyla oluşmaktadır. Farklı şehirlerde uygulanan bu çalışmalar, yapıldığı yerin yerel gazetesiyle kaplanan kutu içinde saklanmaktaydı. Proje hala devam etmektedir. On Kawara'nın işleri hayatta var olma, yaşam ve ölüm gibi kavramların taşıyıcısı gibidir.

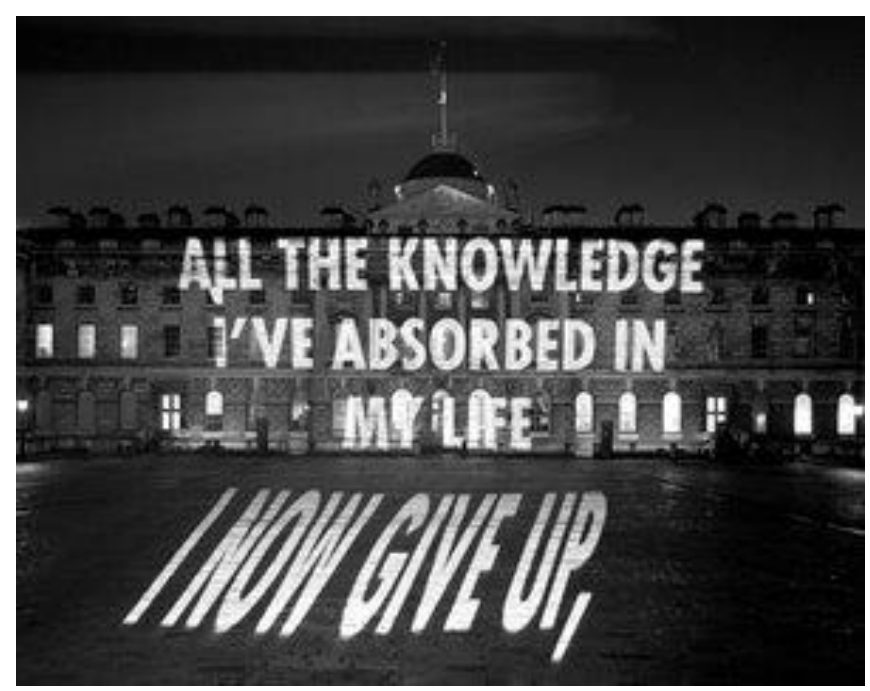

Resim 5. Jenny Holzer

Jenny Holjer'ın neon ışıklarıyla, yazdığı metinlerini görünen noktalara asarak oluşturduğu işleri güçlü göndermeler taşır. İ̧leri reklam panolarını çağrıştıırken, metinleriyle ironik, dolaylı bağlantılar kurdurur. 
Douglas Huebler'in 1969'da ticaret bürosundan Barry, Kosuth ve Weiner'la açtıkları sergi katalogundaki bildirileri şu şekildedir:"Dünya az veya çok ilginç nesnelerle dolu. Bunlara bir yenisini eklemek istemiyorum. Şeylerin varlığını zaman ve/veya uzam sözcükleriyle bildirmekle yetinmeyi yeğliyorum. Çalışma esas olarak, hassas deneyimin ötesinde bulunan şeylerin birbirleriyle ilişkiye sokulmasını hedefliyor. Çünkü çalışma hassas (algısal) deneyimin ötesinde cereyan ediyor. Bir belge sistemi bunun varlığından haberdar olmayı sağlıyor. Belgeler fotoğraf, kart, plan, desen ve "yazılı" betimlemeler biçimindedir." (Gintz, 2010:153)

Haebler, 1969'da "yer işi \#2" isimli işinde, biri Seattle'da diğeri New York'ta yaşayan iki kişiden belirlediği tanımlara uygun fotoğraflar çekmelerini ister. Çekilen 24 fotoğrafı aldıktan sonra içinden hangi tanımlamalara ait olduğunu bilmeden 12 fotoğrafı seçer. Seçtiklerine kendi çektiği 4 fotoğrafı da ekleyerek kültürel yapıyı bozmayı hedefler.

Hans Haecke'nin sanatı gerçekçidir. Gerçeklik; olanı olduğu gibi aktarma durumu ise, O; görünenin arkasındaki gerçekliklerle ilgilenmiştir. Toplumsal konulara eleştirel bakış açısı getirmiştir. "ABD'nin orta Amerika'ya karşı müdahalesine karşı çıkan sanatçılar" grubunun, City University sergisinde, eleştirmen Hilton Kramer, Haecke'nin işi için şunları söylüyordu: 2,5 m'lik beyaz, ahşaptan Donald Judd'un açıklık işini hatırlatan bir küp. Küpün üst yüzeyinde iki küçük açıklık, alt kısımda da şablonla yazılmış birkaç sözcük vardı. Yapıtın etiketinde, tutuklu kamplarında Amerika ordusunca kullanılan tecrit kafesi modeli açıklaması vardı. Haacke'nin böyle bir nesneyi sergi mekânına taşımış olması sadece bir propaganda olmakla kalmaz, ayrıca bu; estetik alanın içinde yer alan sanat düşüncesini de çökertmek demektir. (Gintz, 2010:78-79)

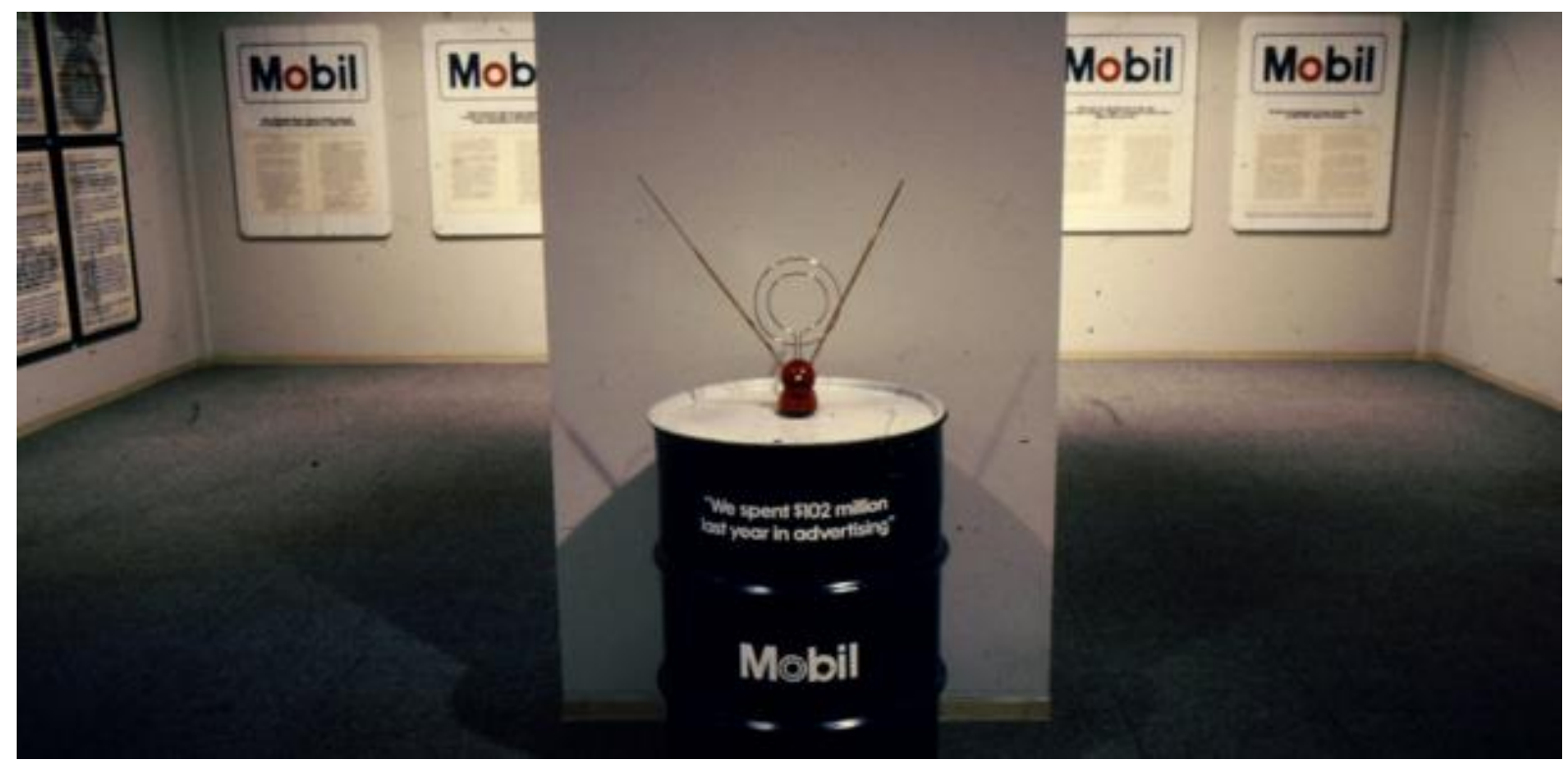

Resim 6. Hans Haacke, Yaratan İzin, 1981

Hans Haacke, mobil petrol şirketleri hakkında ve karışığı kirli işlerle sanata yaptığı maddi sponsorluklarla ilgili belgeler topluyordu. Bu belgeleri mobilin kendi simgeleriyle birlikte galeri duvarına asarak mobilin ikiyüzlü kimliğini ortaya çıkarmıştır. Yapılan bu işler mobil tarafından hiç de sanatsal bulunmamıştır. Mobile ait amblem ve görüntüleri kullanmasını engellemeye çalışmıştır. (Yılmaz, 2005:232) Haacke müze ve galerilerde, sanat yapıtlarına verdiği desteğin arkasındaki siyasi ve ekonomik çıkarları açığa çıkarmaya çaba göstermiştir.

Sonuç olarak kavramsal sanatta öne çıkması istenilen kavram ve düşünce olduğundan, sanatsal üretim şekli daha çok biçimsel metinler olduğu gibi kendini her biçim ve malzemede göstermiştir. 1960'lardan itibaren özellikle performans, Landart, AtePovera eğilimleri yaygınlaşmıştır. Her türlü malzeme, kavram sanatın malzemesi olduğu gibi video da yaygın bir şekilde kullanılmıştır. 1960 ve 1970'lere ait bir akım gibi görünse de hala etkisi güçlüdür. 


\section{Kaynakça}

1. Antmen, A. (2009). 20. Yüzyıl Batı Sanatında Akımlar. İstanbul: Sel Yayıncııık.

2. Atakan, N. (1998). Arayışlar: resimde ve heykelde alternatif akımlar. İstanbul: Y.K.Y.

3. Ergüven, M. (2003). Kurgu Ve Gerçek. İstanbul: Gendaş Kültür.

4. Gintz, C. (2010). Başka Yerde \& Başka Biçimde. Ankara : Dost Kitabevi.

5. Gökteke), J. G. ( 2011). yapıtsız sanat. sanat dünyamız .

6. Lynton, N. (1989). Modern Sanatın Öyküsü. İstanbul: Remzi Kitabevi.

7. Özgür, F. (2004). Laf Lafı Açar, Kavramsal Sanata Giriş 2. RH+ Sanat sayı:25 .

8. Yılmaz, M. (2005). Modernizmden Postmodernizme Sanat. Ankara: Ütopya yayınevi. 